\title{
AVALIAÇÃO DE ADITIVOS DE FASE MÓVEL E TEMPERATURA NA VIDA ÚTIL DE COLUNAS PARA CROMATOGRAFIA LÍQUIDA DE ALTA EFICIÊNCIA
}

\author{
Kátia A. Gomes ${ }^{\text {a }, \text { Allyson L. R. Santos }}{ }^{\mathrm{a}}$ e Anizio M. Faria*a, (1) \\ anstituto de Ciências Exatas e Naturais do Pontal, Universidade Federal de Uberlândia, 38304-402 Ituiutaba - MG, Brasil
}

Recebido em 16/09/2019; aceito em 04/12/2019; publicado na web em 02/03/2020

\begin{abstract}
EVALUATION OF MOBILE PHASE ADDITIVES AND TEMPERATURE ON COLUMN LIFETIME FOR HIGHPERFORMANCE LIQUID CHROMATOGRAPHY. Buffered solutions, additives, and column temperature are widely used in highperformance liquid chromatography to promote adequate retention of compounds and to improve the chromatographic separation. However, these factors can dramatically reduce the column lifetime. In this work, the effect of column temperature, $\mathrm{pH}$ and the salt type and concentration in buffered mobile phases were evaluated on the stability of a typical commercial C18 stationary phase. A method for rapid evaluation of stationary phase degradation caused by these variables was employed to avoid the generation of large volumes of organic waste. By monitoring the performance of stationary phase in the separation of a standard test mixture, it was possible to verify that the $\mathrm{pH}$ of the mobile phase is the most drastic condition to reduce the column lifetime. Buffer solutions of inorganic salts as well as the use of temperatures above $40{ }^{\circ} \mathrm{C}$ also significantly reduce the column lifetime. However, a column can have its use extended working with low concentrations of organic additives in the mobile phase, under moderated temperature, and adjusting the $\mathrm{pH}$ to the safety range of silica-based materials.
\end{abstract}

Keywords: HPLC; stationary phase; column lifetime; inorganic buffers; stability.

\section{INTRODUÇÃO}

O desenvolvimento científico e tecnológico tem levado à geração de novos produtos, funcionais e/ou enriquecidos, que vêm se tornando uma tendência dos principais ramos da indústria na atualidade. ${ }^{1-3} \mathrm{Em}$ especial, o desenvolvimento dos processos de controle de qualidade nos laboratórios analíticos tem garantido que, mesmo com a adição de substâncias funcionais, todos os requisitos de qualidade destes produtos sejam atendidos. A implementação de métodos cromatográficos, em especial da cromatografia líquida de alta eficiência (HPLC, high-performance liquid chromatography), nos laboratórios analíticos de controle de qualidade foi um passo importante para a evolução da produção com tais características. ${ }^{4}$

A HPLC tem como principal característica a capacidade de separar e quantificar substâncias de diferentes polaridades e, associada à espectrometria de massas, identificá-las ou confirmar as suas identidades em uma única medida analítica. Essa versatilidade associada às altas eficiência, exatidão e precisão de resposta torna a HPLC uma ferramenta analítica indispensável nos processos de controle de qualidade de produtos contendo múltiplos princípios ativos, aditivos e/ou componentes enriquecidos. ${ }^{5}$ No entanto, para a separação das espécies químicas de um determinado produto, a HPLC emprega uma coluna cromatográfica que é, dentro dos consumíveis das técnicas analíticas instrumentais, um dos componentes de mais alto custo e de vida útil mais curta, dependendo do tipo de amostra analisada e das condições de análises empregadas. ${ }^{6}$

O principal modo de separação da HPLC é a cromatografia de fase reversa (RP-LC, reversed-phase liquid chromatography), na qual a fase estacionária, contida dentro da coluna, é menos polar que a fase móvel. ${ }^{6} \mathrm{Na}$ RP-LC a fase estacionária é comumente um material a base de sílica modificado quimicamente por moléculas de um agente organossilano com cadeia alquila longa, como $\mathrm{C} 8$ ou C18, enquanto a fase móvel é constituída de uma mistura de solvente orgânico com água/solução aquosa. ${ }^{6,7}$ Para garantir a retenção adequada dos

*e-mail: anizio@ufu.br compostos na fase estacionária, bem como suas separações cromatográficas de forma eficiente, as condições da fase móvel normalmente são ajustadas de acordo com as características das substâncias a serem analisadas.

$\mathrm{O} \mathrm{pH}$ do componente aquoso da fase móvel, o uso de soluções tampão, a presença de aditivos, o ajuste da temperatura da coluna etc. são as principais condições ajustadas na análise cromatográfica por RP-LC. O uso de tampões na fase móvel permite o controle do $\mathrm{pH}$ do componente aquoso e a neutralização de espécies ionizáveis, favorecendo a retenção dos compostos na fase estacionária por interações hidrofóbicas e fornecendo picos cromatográficos simétricos. ${ }^{8-11}$ Assim como as soluções tampão, a temperatura da coluna desempenha papel fundamental no processo cromatográfico. $\mathrm{O}$ aumento da temperatura diminui a viscosidade dos solventes da fase móvel, aumentando a taxa de transferência de massas dos compostos da fase móvel para a fase estacionária, tornando o processo cromatográfico mais eficiente e mais rápido. ${ }^{12-15}$ Por proporcionar uma série de vantagens para o processo de análise cromatográfica, o uso de tampões, $\mathrm{pH}$ ou temperatura na RP-LC podem ser conferidos em quase a totalidade das aplicações cromatográficas registradas na literatura ou implementadas nos processos de controle de qualidade na indústria. ${ }^{16}$ No entanto, essas variáveis podem afetar drasticamente a durabilidade e vida útil da coluna cromatográfica. ${ }^{12,17-21}$ As fases estacionárias convencionais de RP-LC são estáveis apenas na faixa de $\mathrm{pH}$ 2-8. Abaixo de $\mathrm{pH} 2$ ocorre a hidrólise ácida das ligações $\mathrm{Si}-\mathrm{C}$ e, acima de $\mathrm{pH} 8$, ocorre a aceleração da solubilidade do suporte de sílica na fase móvel devido à sua conversão a silicatos. ${ }^{22-24}$ Além disso, o uso de temperaturas elevadas no sistema HPLC na presença de água na fase móvel leva à hidrólise da sílica e perda dos organossilanos, C8 ou C18, ligados quimicamente ao suporte. ${ }^{18}$ Além desses, a presença de cristais do sal do tampão e o tipo de tampão usado também são fatores a serem considerados na durabilidade de uma coluna cromatográfica. ${ }^{21} \mathrm{Em}$ todos os casos a vida útil da coluna cromatográfica pode ser reduzida de forma significativa, gerando um alto custo para os laboratórios analíticos, uma vez que a necessidade de substituição das colunas será constante. 
Considerando que o efeito das condições de análise no tempo de vida das colunas cromatográficas para RP-LC ainda não é bem estabelecido e que muitos usuários de HPLC fazem uso de soluções tampão, aditivos, temperatura etc. para a obtenção de separações eficientes e reprodutivas de compostos nas mais diversas aplicações, neste trabalho a vida útil de uma coluna comercial recheada com uma fase estacionária C18 típica foi avaliada sob diferentes condições de análise. A vida útil da coluna foi avaliada pelo monitoramento de parâmetros cromatográficos, como o número de pratos da coluna, que é um indicador analítico de desempenho do sistema cromatográfico. O método empregado para avaliar a coluna foi baseado na eluição de fase móvel sob condições de degradação da fase estacionária, possibilitando a obtenção da resposta de forma rápida e evitando o funcionamento prolongado do equipamento e o consequente desgaste de seus componentes.

\section{PARTE EXPERIMENTAL}

\section{Materiais}

A fase estacionária empregada para o estudo foi a Kromasil $\mathrm{C}_{18}$ quimicamente ligada, lote 2219, diâmetro de partículas de $5 \mu \mathrm{m}$, diâmetro de poro $100 \AA$ A. Foram empregadas colunas de aço inoxidável $304 \mathrm{~L}$ de $50 \mathrm{~mm} \times 4.0 \mathrm{~mm}$ d.i. Para a preparação das fases móveis foram empregados metanol $(\mathrm{MeOH})$ grau cromatográfico/ espectroscópico da JT Baker (Xalostoc, México) e água grau reagente ASTM tipo II, com resistividade mínima de $18,3 \mathrm{M} \Omega \mathrm{cm}$, obtida em ultrapurificador Megapurity (Billerica, MA, EUA). Os solventes das fases móveis foram filtrados individualmente através de membranas de politetrafluoretileno (PTFE) de 0,22 $\mu \mathrm{m}$ de diâmetro de poros. $\mathrm{Na}_{2} \mathrm{CO}_{3}$ grau ACS (> 99,9\%), $\mathrm{NaHCO}_{3}$ grau ACS $(99,0 \%), \mathrm{NaH}_{2} \mathrm{PO}_{4}$ grau ACS $(99,9 \%), \mathrm{Na}_{2} \mathrm{HPO}_{4}$ grau ACS $(99,9 \%)$ e $\mathrm{CH}_{3} \mathrm{COONH}_{4}$ grau HPLC foram adquiridos da Merck KGaA (Darmstadt, Alemanha). Os compostos empregados no monitoramento dos parâmetros cromatográficos foram: uracil (99\%), benzonitrila (99\%), benzeno $(99,9 \%)$, tolueno $(99,8 \%)$ e naftaleno $(99 \%)$, todos padrões analíticos adquiridos da Sigma-Aldrich (Saint Louis, MO, EUA).

\section{Preparação das colunas cromatográficas}

As colunas cromatográficas avaliadas neste estudo foram preenchidas com fase $\mathrm{C} 18$ quimicamente ligada comercial, de uma mesma marca e mesmo lote, amplamente empregada nas mais diversas aplicações acadêmicas ou industriais. O método de enchimento foi baseado em suspensão balanceada, na qual a fase C18 foi preparada em clorofórmio a $15 \%(\mathrm{~m} / \mathrm{v})$ e deixada sob agitação por $12 \mathrm{~h}$. Em seguida, a suspensão foi submetida ao processo de enchimento à alta pressão, dentro de colunas de aço inox de $50 \mathrm{~mm} \times 4,0 \mathrm{~mm}$ de d.i., em um sistema Restek Pack-in-a-box (Restek, Bellefonte, PA, EUA). O metanol foi empregado como solvente propulsor a uma vazão de $24 \mathrm{~mL} \mathrm{~min}^{-1}$ e pressão de enchimento de aproximadamente 700 bar. Após o enchimento, as colunas cromatográficas foram condicionadas em um sistema cromatográfico Waters modelo Alliance e2695 (Milford, MA, EUA), por $1 \mathrm{~h}$ com fase móvel MeOH: $\mathrm{H}_{2} \mathrm{O}$ $(50: 50, \mathrm{v} / \mathrm{v})$ a $0,4 \mathrm{~mL} \mathrm{~min}^{-1}$.

\section{Avaliação de condições de análise na vida útil de colunas cromatográficas}

O uso de aditivos em fases móveis e de temperatura são muito comuns para a obtenção de separações eficientes e picos simétricos em métodos cromatográficos de análise. Algumas das condições mais empregadas foram avaliadas quanto a estabilidade e vida útil da coluna recheada com C18: ajuste de $\mathrm{pH}$, tampões, concentração dos aditivos, temperatura e composição da fase móvel. O estudo foi realizado de forma univariada, alterando as condições de uma variável e fixando todas demais.

O método de avaliação consistiu na passagem contínua da fase móvel pela coluna cromatográfica recheada com a fase estacionária por 30 min (degradação), seguida da separação de uma mistura de compostos padrão (uracila, benzonitrila, benzeno, tolueno e naftaleno) para monitoramento das propriedades de retenção e de desempenho da fase C18 (análise). Os parâmetros avaliados foram o número de pratos $(\mathrm{N})$ e o fator de retenção $(\mathrm{k})$ para o pico do naftaleno, composto mais retido na fase estacionária. Cada etapa de degradação associada à etapa de análise correspondeu a um ciclo. Para a avaliação do efeito de cada variável foram definidos pelo menos 36 ciclos, um dia de análise, suficiente para degradar a fase estacionária e avaliar sua resistência às variações das condições da fase móvel.

\section{Efeito do $\mathrm{pH}$}

Para avaliar o efeito do $\mathrm{pH}$ na estabilidade da fase estacionária, três condições fora da faixa de estabilidade de fases à base de sílica foram avaliadas: pH 9, 10 e 11, visando acelerar a degradação da fase C18. Para avaliar o efeito do $\mathrm{pH}$ na vida útil da fase C18 as seguintes condições foram fixadas: fase móvel MeOH:tampão fosfato a $0,050 \mathrm{~mol} \mathrm{~L}^{-1}(60: 40, \mathrm{v} / \mathrm{v})$, temperatura de $50{ }^{\circ} \mathrm{C}$, vazão de $0,4 \mathrm{~mL} \mathrm{~min}^{-1}$.

\section{Efeito da temperatura}

A temperatura na separação por cromatografia líquida desempenha um papel fundamental que vai desde o aumento da velocidade da fase móvel e da taxa de transferência de massa do soluto da fase móvel para a fase estacionária até a melhora da seletividade. ${ }^{12-14} \mathrm{O}$ efeito da temperatura na estabilidade da fase estacionária quimicamente ligada à base de sílica foi avaliado em três níveis: $40^{\circ} \mathrm{C}, 45^{\circ} \mathrm{C}$ e $50^{\circ} \mathrm{C}$. As demais condições de análise foram fixadas: fase móvel $\mathrm{MeOH}$ :tampão fosfato $\mathrm{pH} 10,00$ a $0,050 \mathrm{~mol} \mathrm{~L}^{-1}\left(60: 40\right.$, v/v), vazão de $0,4 \mathrm{~mL} \mathrm{~min}^{-1}$.

Efeito do uso de tampões: tipo, concentração e proporção na fase móvel

Para avaliar a influência que o uso de soluções tampões na fase móvel apresentam sobre a vida útil de uma coluna cromatográfica recheada com fase $\mathrm{C} 18$ foram testados três diferentes tipos de tampões: inorgânicos (fosfato de sódio e carbonato de sódio) e orgânico (acetato de amônio). Os tampões foram avaliados em concentrações de $0,001 \mathrm{~mol} \mathrm{~L}^{-1}, 0,025 \mathrm{~mol} \mathrm{~L}^{-1}$ e $0,050 \mathrm{~mol} \mathrm{~L}^{-1}$. A composição da fase móvel também foi avaliada quanto a proporção do componente aquoso (soluções tampão) em 60\%, 50\% e 40\%. As demais condições de análise foram fixadas em $\mathrm{pH} 10,00$, temperatura de $45^{\circ} \mathrm{C}$ e vazão de $0,4 \mathrm{~mL} \mathrm{~min}^{-1}$.

\section{Caracterização da fase estacionária C18}

Após avaliados os efeitos das condições de análise na vida útil da fase C18 quimicamente ligada a base de sílica, uma coluna recheada com a fase $\mathrm{C} 18$ foi submetida a um teste de degradação empregando fase móvel MeOH:tampão fosfato $\mathrm{pH} 10,00$ a $0,025 \mathrm{~mol} \mathrm{~L}^{-1}$, vazão de $0,4 \mathrm{~mL} \mathrm{~min}^{-1} \mathrm{e}$ temperatura de $45^{\circ} \mathrm{C}$. Após o teste, o material de fase estacionária foi removido do interior da coluna, seco em estufa a $120^{\circ} \mathrm{C}$ por $1 \mathrm{~h}$ e submetido à caracterização.

A fase C18 foi caracterizada morfologicamente antes e após a degradação por microscopia eletrônica de varredura em um microscópico TESCAN modelo Vega3 (Tóquio, Japão) a 20 kV. A densidade de moléculas C18 na fase após a degradação foi avaliada por análise termogravimétrica na faixa de temperatura de 25 a $600{ }^{\circ} \mathrm{C}$ com taxa de aquecimento de $10{ }^{\circ} \mathrm{C} \mathrm{min}^{-1} \mathrm{sob}$ atmosfera de $\mathrm{N}_{2}$ em um analisador 
termogravimétrico da TA Instruments modelo TGA-55 (New Castle, DE, EUA). A estrutura de poros e área superficial específica da fase C18 foram avaliadas pela técnica de fisissorção de nitrogênio com isoterma de BET em um equipamento ASAP modelo 2020 plus da Micromeritics (Norcross, GA, EUA).

\section{RESULTADOS E DISCUSSÃO}

A vida útil de uma coluna cromatográfica é dependente de uma série de fatores, desde o tipo de amostra e analitos até as condições cromatográficas de análise (fase móvel, temperatura, qualidade e pureza dos solventes etc.). Como os analitos e amostras são intrínsecos à determinações específicas, este estudo buscou avaliar o efeito que as condições mais usualmente empregadas em análises cromatográficas possuem sobre a estabilidade química das fases estacionárias reversas: $\mathrm{pH}$ do componente aquoso da fase móvel, aditivos de fase móvel, tampões e temperatura. Para monitorar a resistência das fases estacionárias às ações das diferentes condições de análise foram realizadas separações periódicas de uma mistura de compostos padrão, durante a passagem de fase móvel em condições de degradação. Parâmetros cromatográficos dos compostos como número de pratos, fator de retenção e resolução foram medidos nos cromatogramas de separação da mistura teste. $\mathrm{O}$ número de pratos pode ser considerado um excelente parâmetro para monitorar a resistência da fase estacionária às condições de degradação uma vez que a morte da coluna, perda da capacidade de separação e de desempenho da fase estacionária, é registrada por uma queda brusca deste parâmetro, normalmente abaixo de $50 \%$ do seu valor inicial. ${ }^{25}$ Apesar de em alguns casos a separação ainda ocorrer após a queda do número de pratos pela metade do valor inicial, parâmetros analíticos do método cromatográfico ("system suitability") empregando essa coluna são perdidos, tais como a repetibilidade, limite de detecção, resolução etc., devido ao alargamento e perda de simetria dos picos cromatográficos. ${ }^{20}$ Dessa forma, a vida útil das fases estacionárias foram medidas pela perda de eficiência da coluna cromatográfica quando seu número de pratos reduziu a menos de $50 \%$ do valor inicial.

Como uma coluna cromatográfica pode apresentar uma durabilidade de meses e até anos, dependendo das condições de fase móvel empregadas nas rotinas de análises, e sabendo que a estabilidade química das fases estacionárias $\mathrm{C} 18$ quimicamente ligadas convencionais estão na faixa de $\mathrm{pH} 2$ a 8 , todos os testes foram realizados em condições alcalinas de fase móvel combinadas com altas concentrações de sais (aditivos) e temperatura para que a avaliação ocorresse de forma rápida, evitando o funcionamento prolongado do equipamento e o desgaste da lâmpada do detector, das bombas de alta pressão e o aumento do risco de entupimento das tubulações.

\section{Efeito do pH na vida útil da coluna recheada com fase C18}

Apesar de atualmente algumas fases reversas disponíveis comercialmente apresentarem tecnologias que estendem sua faixa de estabilidade até $\mathrm{pH} 12,{ }^{26}$ devido ao alto custo delas, a maioria das aplicações ainda envolvem fases C18 quimicamente ligadas e capeadas. No entanto, o ajuste de $\mathrm{pH}$ da fase móvel é uma condição muito realizada em diversas separações no modo de fase reversa, em especial, de moléculas com características básicas, para neutralização de suas cargas elétricas e consequente aumento de retenção na fase C18. Dessa forma, a avaliação do efeito do $\mathrm{pH}$ na vida útil de uma coluna comercial recheada com uma fase $\mathrm{C} 18$ convencional foi realizada em três diferentes condições pH 9, 10 e 11, monitorando os parâmetros cromatográficos: número de pratos $(\mathrm{N})$ e o fator de retenção $(\mathrm{k})$ para o pico do naftaleno na mistura teste padrão. A Figura 1 apresenta os resultados que relacionam a eficiência de coluna com a passagem de fase móvel em diferentes valores de $\mathrm{pH}$.

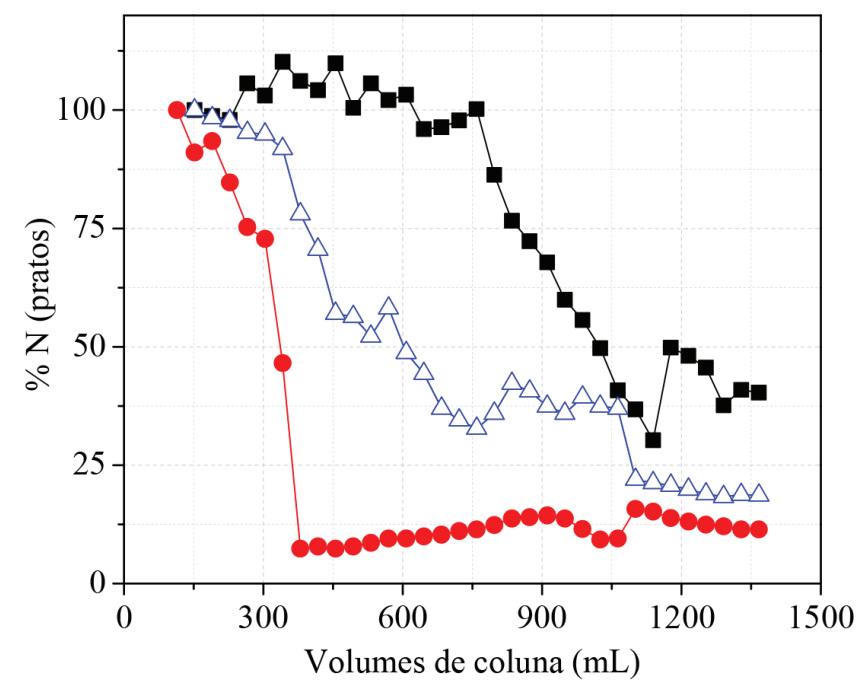

Figura 1. Variação do número de pratos em uma fase C18 quimicamente

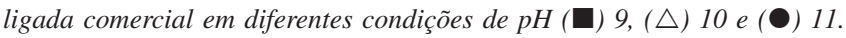
Condições de análise: fase móvel MeOH:0,050 mol L-1 $\mathrm{NaH}_{2} \mathrm{PO}_{4}, 60: 40$ $(v / v)$, vazão $0,4 \mathrm{~mL} \mathrm{~min}{ }^{-1}$, temperatura de $50{ }^{\circ} \mathrm{C}$ e detecção $U V$ a $254 \mathrm{~nm}$. Soluto teste: naftaleno

A degradação da fase estacionária $\mathrm{C} 18$ à base de sílica é fortemente acelerada com o aumento do $\mathrm{pH}$ da fase móvel (Figura 1). $\mathrm{O}$ aumento do $\mathrm{pH}$ de 9 para 11 reduziu a vida útil da coluna cromatográfica em 2/3, de cerca de 1000 para 330 volumes de coluna. Isso ocorreu devido ao aumento de grupos hidroxilas na fase móvel, que leva à conversão mais rápida de $\mathrm{SiO}_{2}$ para $\mathrm{SiO}_{3}{ }^{-}$. Em fases $\mathrm{C} 18$ quimicamente ligadas o suporte de sílica não é totalmente protegido pelas moléculas do grupamento organossilano devido ao impedimento estérico causado pela inserção de moléculas do C18, altamente volumosas, a grupos silanóis $(\mathrm{Si}-\mathrm{OH})$ vizinhos da superfície e poros da sílica. ${ }^{23}$ Assim, parte do suporte fica exposto ao contato com a fase móvel que, sob condições alcalinas, leva à destruição do leito cromatográfico. $\mathrm{O}$ pH da fase móvel é a condição experimental mais agressiva para a fase estacionária, sendo observado um vazio dentro da coluna cromatográfica após a passagem da fase móvel em $\mathrm{pH}$ 11, conforme verificado na Figura 1S (Material Suplementar). Para avaliação do efeito de outras condições de análise na durabilidade da coluna cromatográfica recheada com C18 a fase móvel foi ajustada para $\mathrm{pH} 10$, por fornecer uma análise rápida, porém suficiente para avaliar pequenas diferenças na ação de outras variáveis experimentais na vida útil da fase estacionária.

Outro parâmetro monitorado durante a passagem de fase móvel em diferentes condições de $\mathrm{pH}$ pela fase estacionária foi o fator de retenção. No entanto, o fator de retenção não é um parâmetro adequado para avaliação do efeito de uma condição experimental sobre a resistência da fase estacionária, uma vez que não é possível identificar o momento de morte da coluna cromatográfica, como pode ser observado na Figura 2. Observa-se apenas a contínua redução do fator de retenção ao longo da passagem de fase móvel, sendo a taxa de perda mais acentuada à medida que se aumenta o pH do componente aquoso. Isso ocorre devido à perda contínua e constante das moléculas de C18 ligadas quimicamente na superfície da sílica, lixiviando-as da coluna, sem nenhum pico de perda significativa de fase estacionária ao longo do estudo.

\section{Efeito da temperatura}

A temperatura é outra condição de análise empregada para melhoria da separação cromatográfica em inúmeras aplicações da 


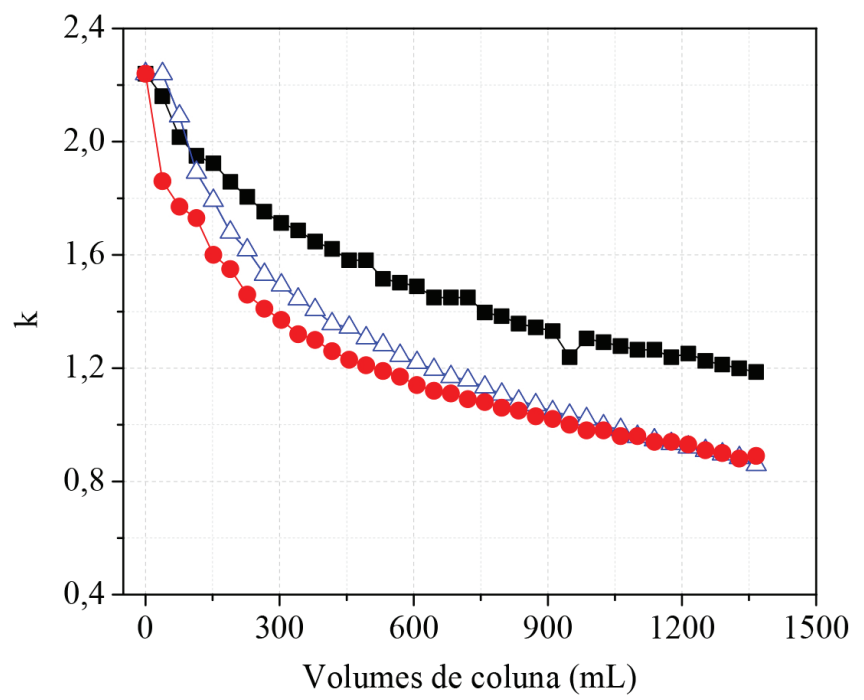

Figura 2. Variação do fator de retenção $(k)$ em uma fase C18 quimicamente

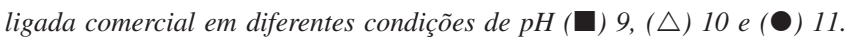
Condições de análise: fase móvel MeOH:0,050 mol $\mathrm{L}^{-1} \mathrm{NaH}_{2} \mathrm{PO}_{4}, 60: 40$ $(v / v)$, vazão $0,4 \mathrm{~mL} \mathrm{~min}^{-1}$, temperatura de $50{ }^{\circ} \mathrm{C}$ e detecção $U V$ a $254 \mathrm{~nm}$. Soluto teste: naftaleno

RP-LC. O aumento da temperatura no processo cromatográfico reduz a viscosidade dos solventes da fase móvel, aumentando a taxa de transferência de massa dos solutos da fase móvel para a fase estacionária e vice-versa. Consequentemente, o aumento da temperatura da coluna normalmente resulta em separações mais eficientes, com picos cromatográficos mais estreitos e melhor resolução entre os picos. Por esses e vários outros motivos, como a redução da pressão do sistema cromatográfico, maior velocidade linear da fase móvel (menor tempo de análise) etc., o uso de temperaturas acima da ambiente em RP-LC é explorada com frequência em separações analíticas. Por outro lado, o seu efeito sobre a vida útil da fase estacionária não está suficientemente esclarecido. Fases estacionárias $\mathrm{C} 18$ convencionais têm uso recomendado normalmente até $60^{\circ} \mathrm{C}$, apesar da existência de outros materiais resistentes a temperaturas $>150{ }^{\circ} \mathrm{C}$, uma vez que o efeito de hidrólise das ligações entre o $\mathrm{C} 18$ e a sílica é aumentado com o aumento da temperatura. ${ }^{12,26}$ Dessa forma, avaliou-se a influência de temperaturas usualmente empregadas nas separações analíticas como 40,45 e $50{ }^{\circ} \mathrm{C}$ sobre uma fase estacionária $\mathrm{C} 18$ típica em condições extremas de degradação ( $\mathrm{pH}$, tampões, concentrações elevadas) para aceleração do estudo, pelos motivos já mencionados.

A Figura 3 mostra como o aumento da temperatura leva à diminuição da vida útil da coluna cromatográfica, devido à aceleração da perda de desempenho da fase estacionária. Com o aumento da temperatura, ocorre a diminuição da viscosidade da fase móvel, fazendo com que microporos e poros capilarizados da fase estacionária tenham maior acesso dos solventes, levando à dissolução da sílica a partir desses associada ao favorecimento da reação de hidrólise entre as moléculas $\mathrm{C} 18$ e a superfície da sílica. O aumento da temperatura, no entanto, parece ter um efeito exponencial na redução da vida útil da coluna, de $45{ }^{\circ} \mathrm{C}$ para $50{ }^{\circ} \mathrm{C}$ a degradação ocorre de forma mais acelerada se comparada com a perda de eficiência observada no aumento de $40{ }^{\circ} \mathrm{C}$ para $45^{\circ} \mathrm{C}$. Dessa forma, o ganho na separação cromatográfica com o uso de temperatura de coluna de $50{ }^{\circ} \mathrm{C}$ não parece compensar a redução, pela metade, da vida útil da coluna se a temperatura fosse mantida a $40{ }^{\circ} \mathrm{C}$. Ainda na Figura 3 pode ser observada a elevação da eficiência de coluna (número de pratos) nas temperaturas de 40 e $45^{\circ} \mathrm{C}$ ao longo da avaliação. Esse aumento se deve, provavelmente, ao contínuo acesso da fase móvel a microporos da fase estacionária, encontrando novos sítios ativos de interação

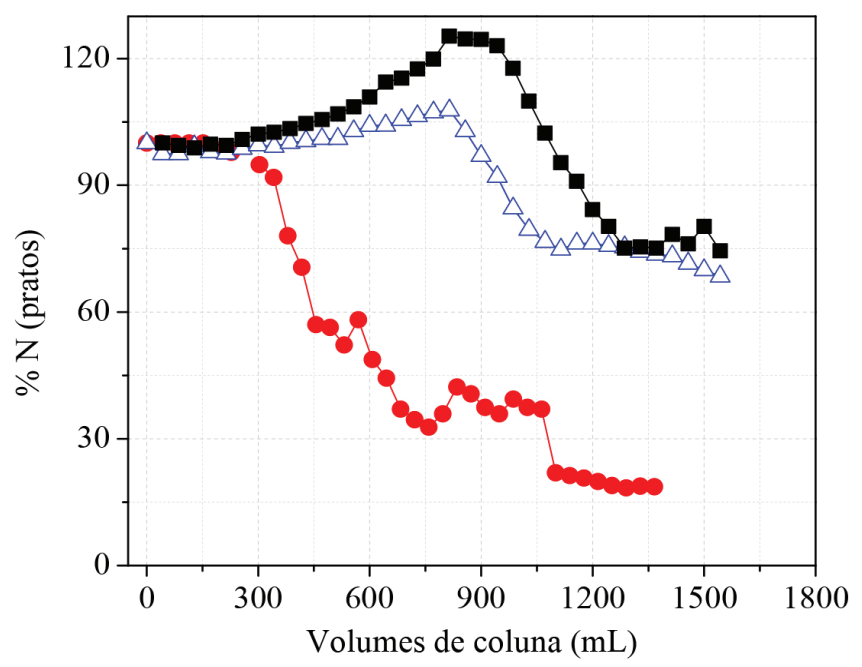

Figura 3. Variação do número de pratos em uma fase C18 quimicamente ligada comercial em diferentes condições de temperatura $(\square) 40{ }^{\circ} \mathrm{C},(\triangle) 45^{\circ} \mathrm{Ce}$ (O) $50{ }^{\circ} \mathrm{C}$. Condições de análise: fase móvel MeOH:0,050 mol L-1 $\mathrm{NaH}_{2} \mathrm{PO}_{4}$ a pH 10, 60:40 (v/v), vazão 0,4 $\mathrm{mL} \mathrm{min}^{-1}$ e detecção UV a $254 \mathrm{~nm}$. Soluto teste: naftaleno

soluto-fase estacionária associado ao aumento da taxa de transferência de massa do soluto na fase móvel.

Para avaliação do efeito de outras variáveis na estabilidade da fase $\mathrm{C} 18$ comercial, a temperatura da coluna foi fixada em $45^{\circ} \mathrm{C}$.

\section{Efeito do uso de tampões na vida útil da coluna cromatográfica}

As soluções tampão como componente aquoso das fases móveis para RP-LC desempenham um importante papel na separação cromatográfica, pois evitam a variação do $\mathrm{pH}$ da fase móvel (seja pela solubilização de $\mathrm{CO}_{2}$ atmosférico ou pela evaporação de aditivos) e, consequentemente, impedem a variação da retenção e seletividade dos analitos, em especial aqueles ionizáveis. ${ }^{9}$ Por esse motivo, o uso de tampão em separações cromatográficas é quase que indispensável para a garantia de um método de separação preciso e seletivo. Por outro lado, as soluções tampão podem também ser altamente prejudiciais ao processo cromatográfico, desde o entupimento de tubulações e da cela de detecção até a destruição do leito cromatográfico das colunas. ${ }^{17} \mathrm{O}$ efeito do uso de tampões (tipo, concentração e porcentagem na composição da fase móvel) foi avaliado sobre a vida útil de uma fase C18 típica. Inicialmente foi realizado um estudo sobre o efeito do tipo de tampão empregado na separação cromatográfica. Dois tampões inorgânicos, fosfato e carbonato, e um tampão orgânico, acetato de amônio, foram avaliados sobre o desempenho cromatográfico da fase estacionária C18 para a separação de uma mistura teste padrão, Figura 4.

Nas condições de estudo, as soluções aquosas de fosfato e de tampão carbonato apresentaram a mesma taxa de redução da vida útil da fase estacionária $\mathrm{C} 18$, sendo essa taxa muito maior que a apresentada pelo uso do tampão acetato de amônio. Dentro do período investigado, a fase móvel tamponada com acetato de amônio não foi capaz de provocar a morte da coluna cromatográfica, não sendo registrada a queda brusca do número de pratos ao longo do estudo, mesmo empregando fase móvel ajustada a pH 10 e temperatura de coluna de $45^{\circ} \mathrm{C}$. Logo, o uso de fases móveis tamponadas com tampões orgânicos, além de possibilitar um acoplamento mais eficiente com o espectrômetro de massas, é menos agressivo para a fase estacionária, minimizando a redução drástica de sua vida útil. No entanto, é possível observar que tampões inorgânicos apresentam efeito mais degradante para a fase estacionária. Dentre as soluções 


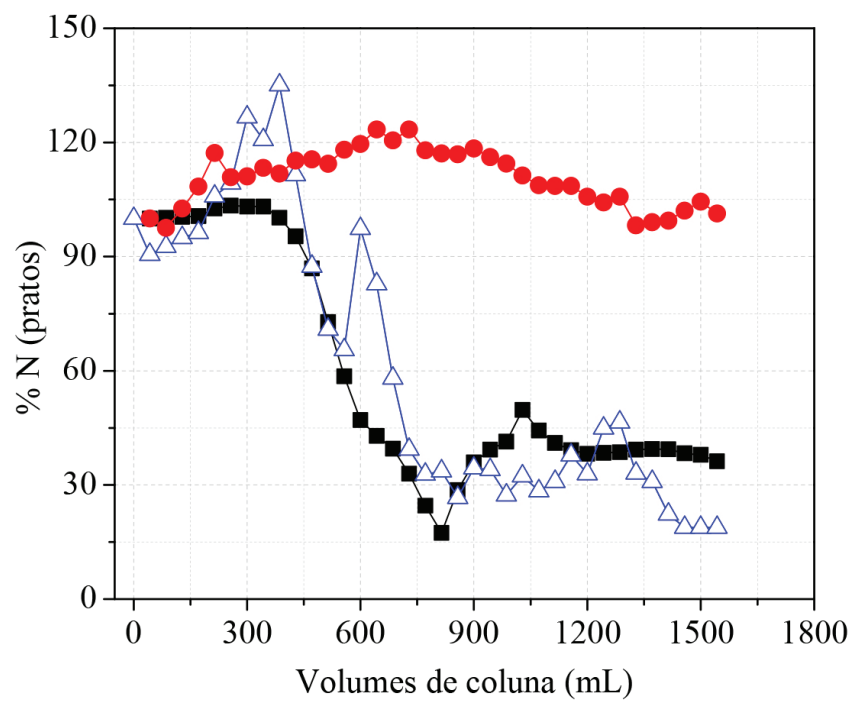

Figura 4. Variação do número de pratos em uma fase C18 quimicamente ligada comercial em diferentes condições de componente aquoso da fase móvel: (ロ) sol. $\mathrm{Na}_{2} \mathrm{HPO}_{4},(\triangle)$ sol. $\mathrm{Na}_{2} \mathrm{CO}_{3}$ e (O) sol. $\mathrm{CH}_{3} \mathrm{COONH}_{4}$. Condições de análise: fase móvel MeOH:0,050 mol $\mathrm{L}^{-1}$ sol. tampão a pH 10, 60:40 $(v / v)$, vazão 0,4 mL min ${ }^{-1}$, temperatura de $45{ }^{\circ} \mathrm{C}$ e detecção $U V$ a $254 \mathrm{~nm}$. Soluto teste: naftaleno

inorgânicas investigadas, o tampão carbonato apresentou uma maior variação do número de pratos para o pico do naftaleno, o que significa um ataque mais agressivo ao leito cromatográfico em comparação com a fase móvel preparada com solução fosfato. Nesse caso, podem ter ocorrido rearranjos das partículas da fase estacionária, devido à dissolução do leito, no interior da coluna provocando oscilação da eficiência de coluna quando da passagem da fase móvel em tampão carbonato. Na literatura verifica-se que, normalmente, tampões carbonato possuem maior ação sobre a fase estacionária, levando-a a uma degradação mais rápida, o que corrobora com essa hipótese. ${ }^{17,21}$

A solução fosfato foi mantida como o componente aquoso da fase móvel para avaliar o efeito da concentração do sal na estabilidade química da fase $\mathrm{C} 18$. Concentrações de tampões inorgânicos maiores que $0,050 \mathrm{~mol} \mathrm{~L}^{-1}$ são eficientes no tamponamento da fase móvel, porém, podem aumentar o grau de solubilidade da fase estacionária na fase móvel ou deteriorar a fase estacionária devido à precipitação do sal na porção orgânica da fase móvel, levando até ao bloqueio do fluxo de fase móvel. ${ }^{17}$ Para o estudo do efeito da concentração do tampão da fase móvel na estabilidade química de fases estacionárias três concentrações de $\mathrm{Na}_{2} \mathrm{HPO}_{4}$ foram avaliadas: 0,050; 0,025 e $0,001 \mathrm{~mol} \mathrm{~L}^{-1}$, monitorando o número de pratos da coluna para o pico do naftaleno, Figura 5.

A concentração da solução aquosa do sal apresenta um efeito altamente agressivo na resistência da fase estacionária. Concentrações baixas como $0,001 \mathrm{~mol} \mathrm{~L}^{-1} \mathrm{de} \mathrm{Na}_{2} \mathrm{HPO}_{4}$, dentro do período investigado, não foi capaz de destruir o leito cromatográfico, mesmo empregando condições alcalinas e temperatura mais elevada no estudo. No entanto, a vida útil da fase $\mathrm{C} 18$ é reduzida progressivamente com o aumento da concentração do sal. Se por um lado a alta concentração dos sais do tampão garantem uma maior capacidade tamponante da fase móvel e uma menor variação da retenção dos compostos, sobretudo os ionizáveis na fase estacionária, por outro observa-se que concentrações elevadas do tampão aumentam a taxa de degradação da fase C18, além de incorrer no risco de entupimento das tubulações do sistema cromatográfico devido à precipitação do sal.

O efeito da composição da fase móvel, porcentagem de componente aquoso, na resistência da fase $\mathrm{C} 18$ quimicamente ligada também foi avaliado através do monitoramento do número de pratos da coluna

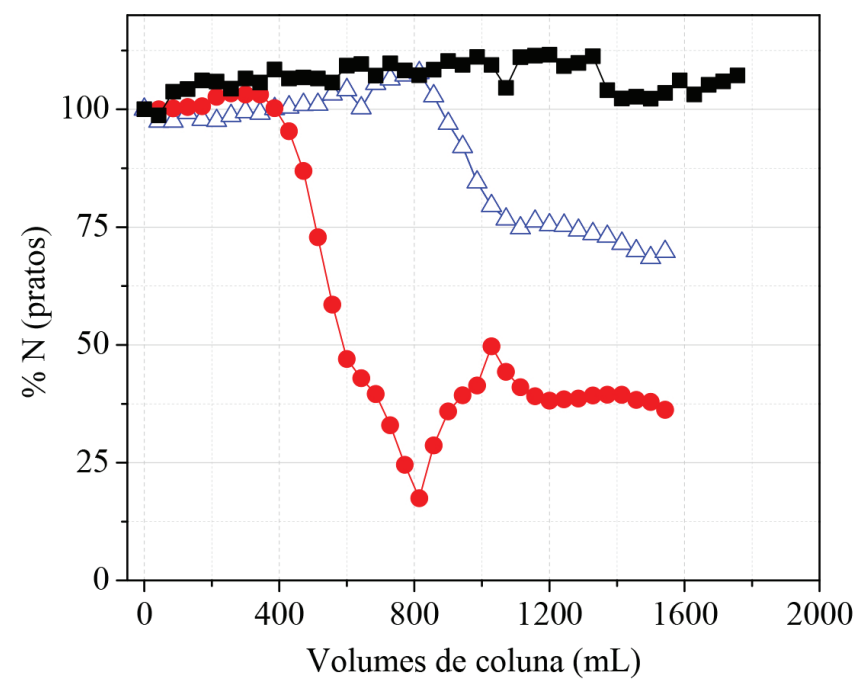

Figura 5. Variação do número de pratos em uma fase C18 quimicamente ligada comercial em diferentes concentrações da solução de $\mathrm{Na}_{2} \mathrm{HPO}_{4}$ na fase

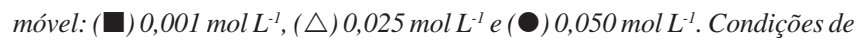
análise: fase móvel MeOH:sol. $\mathrm{Na}_{2} \mathrm{HPO}_{4}$ a pH 10, 60:40 (v/v), vazão 0,4 $\mathrm{mL}$ $\mathrm{min}^{-1}$, temperatura de $45^{\circ} \mathrm{C}$ e detecção UV a $254 \mathrm{~nm}$. Soluto teste: naftaleno

para o pico do naftaleno. Foram avaliadas fases móveis com 40, 50 e $60 \%$ de componente aquoso, sol. $\mathrm{Na}_{2} \mathrm{HPO}_{4}$ a $0,025 \mathrm{~mol} \mathrm{~L}-1$, e os resultados obtidos são apresentados na Figura 6.

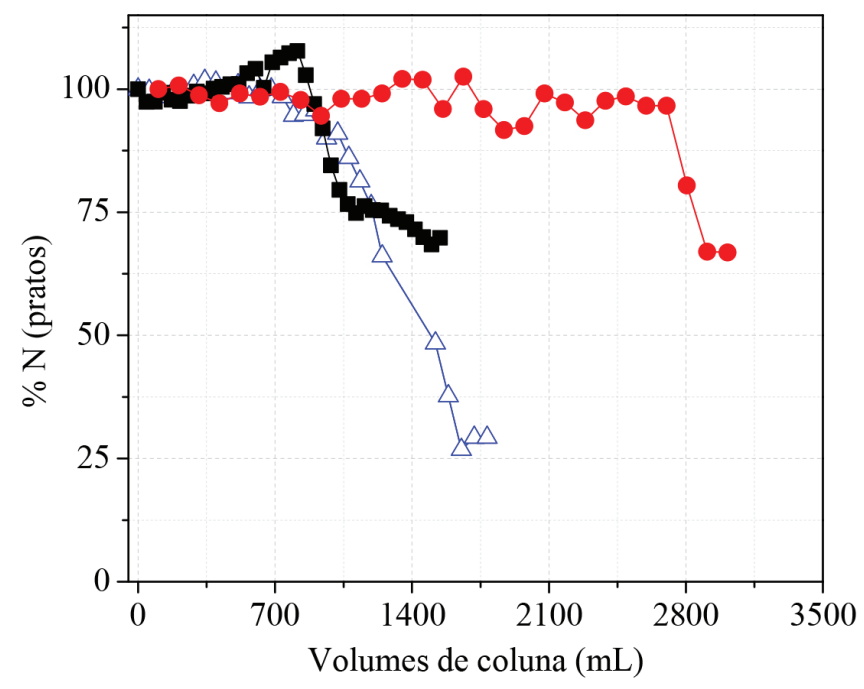

Figura 6. Variação do número de pratos em uma fase C18 quimicamente ligada comercial sob diferentes composições da fase móvel: (ם) 60:40, $(\triangle)$ ) 50:50 $e\left(-10: 60(v / v)\right.$. Condições de análise: fase móvel MeOH:0,025 mol L $L^{-1}$ de sol. $\mathrm{Na}_{2} \mathrm{HPO}_{4}$ a pH 10, vazão $0,4 \mathrm{~mL} \mathrm{~min}{ }^{-1}$, temperatura de $45^{\circ} \mathrm{C}$ e detecção UV a $254 \mathrm{~nm}$. Soluto teste: naftaleno

De acordo com a Figura 6, o aumento da porcentagem de componente aquoso leva a um prolongamento da vida útil da coluna, principalmente quando superior a $50 \%$ da fase móvel. As viscosidades da mistura metanol:água na temperatura analisada equivalem a 1,00; 1,02 e 0,98 cP para as proporções com 40,50 e $60 \%$ de metanol na fase móvel, respectivamente. ${ }^{16}$ Quanto menor a viscosidade da fase móvel, maior é o acesso a microporos e poros capilarizados das partículas de fase estacionária, levando a uma degradação mais rápida da fase estacionária. Nesse caso, a contribuição da viscosidade na taxa de degradação do material é pequena. No entanto, o aumento do teor de solvente orgânico na fase móvel aumenta o valor do pKa 
do ácido usado para a preparação da solução tampão, aumentando o $\mathrm{pH}$ da fase móvel e, dessa forma, degradando mais rapidamente a fase estacionária. ${ }^{9}$ No entanto, fases reversas como a C18 sofrem colapso das cadeias alquilas quando porcentagens elevadas de água ou soluções aquosas, $>90 \%$, são empregadas na fase móvel. ${ }^{23}$

\section{Propriedades da fase C18 antes e após o estudo de degradação}

Para avaliação das características morfológicas e químicas da fase C18 após o estudo de degradação, porções do material foram retiradas de dentro das colunas de aço inox, secadas em estufa a $60{ }^{\circ} \mathrm{C}$ por $1 \mathrm{~h}$ e, posteriormente, caracterizadas por técnicas como análise termogravimétrica, microscopia eletrônica de varredura e análise de área superficial específica e porosidade. De acordo com a Tabela 1, observa-se que ocorre um ligeiro aumento das propriedades morfológicas das partículas de sílica-C18 após o teste de degradação, confirmando o ataque da fase móvel à sua estrutura de poros e alterando a área superficial específica devido à solubilização de parte do suporte de sílica. As partículas da fase estacionária também perdem a regularidade de seu formato esférico (Figura 2S, Material Suplementar), comprovando a dissolução parcial das partículas com a passagem da fase móvel degradante para a sílica.

Tabela 1. Propriedades da fase estacionária C18 quimicamente ligada antes e após o estudo de degradação. Condições de análise: fase móvel MeOH:0,025 mol L-1 de sol. $\mathrm{Na}_{2} \mathrm{HPO}_{4}$ a pH 10 (60:40, v/v), vazão de $0,4 \mathrm{~mL} \mathrm{~min}^{-1}$, temperatura de $45^{\circ} \mathrm{C}$

\begin{tabular}{lcc}
\hline Propriedades da fase C18 comercial & $\begin{array}{c}\text { Antes da } \\
\text { degradação }\end{array}$ & Após a degradação \\
\hline Área superficial específica / $\mathrm{m}^{2} \mathrm{~g}^{-1}$ & $163,1 \pm 0,7$ & $169,8 \pm 1,9$ \\
Volume de poros / $\mathrm{cm}^{3} \mathrm{~g}^{-1}$ & $0,51 \pm 0,2$ & $0,54 \pm 0,2$ \\
Diâmetro de poros / $\mathrm{nm}$ & $12,55 \pm 0,4$ & $12,74 \pm 0,9$ \\
\hline
\end{tabular}

Após a queda brusca do número de pratos da coluna cromatográfica, registrada neste estudo para o pico do naftaleno, é possível observar também que a capacidade de separação da fase C18 é perdida totalmente, bem como as características de desempenho do método, Figura 7.

\section{CONCLUSÃO}

De acordo com os resultados apresentados neste estudo, pode-se concluir que condições experimentais de análise amplamente empregadas nas mais diversas separações cromatográficas afetam a durabilidade da coluna recheada com fase estacionária C18 quimicamente ligada para cromatografia líquida de alta eficiência no modo de fase reversa. Apesar da importância do uso de tampões, da temperatura e do ajuste de $\mathrm{pH}$ para garantir eficiência e repetibilidade das análises cromatográficas para diversas substâncias, a vida útil das colunas cromatográficas é reduzida significativamente sob tais condições, principalmente se combinadas. $\mathrm{O}$ pH, o tipo de tampão e a concentração do sal na fase móvel são, nessa ordem, as variáveis que afetam mais drasticamente a vida útil da coluna cromatográfica. A temperatura de coluna também acelera a degradação da fase estacionária, em especial, acima de $40{ }^{\circ} \mathrm{C}$. No entanto, o uso de tampões de sais orgânicos, em concentrações mais baixas e com temperaturas inferiores a $40{ }^{\circ} \mathrm{C}$ podem garantir longevidade ao uso das colunas cromatográficas, bem como eficiência e repetibilidade de retenção para os solutos, devido ao efeito menos drástico de degradação da fase estacionária.

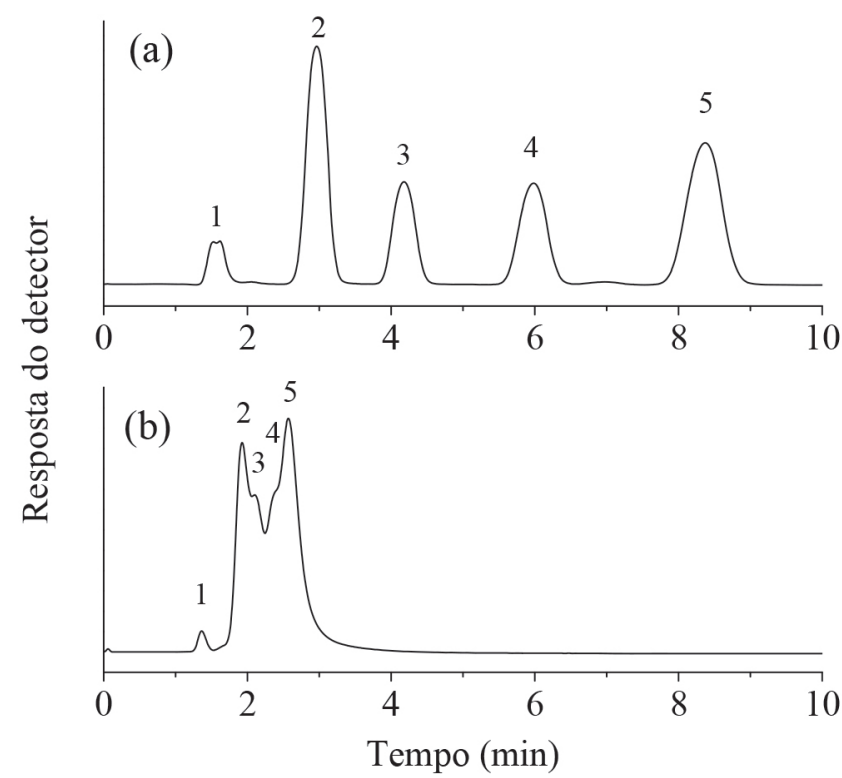

Figura 7. Cromatograma da separação de mistura teste padrão em uma fase C18 quimicamente ligada comercial (a) antes $e(b)$ após o estudo de degradação. Condições de análise: fase móvel MeOH:0,025 mol L $\mathrm{L}^{-1}$ de sol. $\mathrm{Na}_{2} \mathrm{HPO}_{4}$ a pH 10 (60:40, v/v), vazão 0,4 $\mathrm{mL} \mathrm{min}^{-1}$, temperatura de $45^{\circ} \mathrm{Ce}$ detecção UV a $254 \mathrm{~nm}$. Identificação dos compostos: 1- uracil, 2- benzonitrila, 3- benzeno, 4-tolueno e 5-naftaleno

\section{MATERIAL SUPLEMENTAR}

Algumas informações e resultados complementares deste trabalho estão disponíveis em http://quimicanova.sbq.org.br, na forma de arquivo PDF, com acesso livre.

\section{AGRADECIMENTOS}

Os autores agradecem à Financiadora de Estudos e Projetos [processos 01.11.0135.00 e 01.13.0371.00], à Coordenação de Aperfeiçoamento de Pessoal de Nível Superior (CAPES, Código de Financiamento 001) e à Fundação de Amparo à Pesquisa do Estado de Minas Gerais (FAPEMIG) pelo apoio financeiro. Os autores agradecem também ao laboratório multiusuário do Instituto de Química da Universidade Federal de Uberlândia pelas análises e suporte técnico envolvendo a microscopia eletrônica de varredura.

\section{REFERÊNCIAS}

1. Eussen, S. R. B. M.; Verhagen, H.; Klungel, O. H.; Garssen, J.; van Loveren, H.; van Kranen, H. J.; Rompelberg, C. J. M.; Eur. J. Pharmacol. 2011, 668, S2.

2. Koller, M.; Muhr, A.; Braunegg, G.; Algal Res. 2014, 6, 52.

3. Lobo, V.; Patil, A.; Phatak, A.; Chandra, N.; Pharmacogn. Rev. 2010, 4, 118.

4. Masson, P.; J. Chromatogr. A 2007, 1158, 168.

5. Höllein, L.; Holzgrabe, U.; Pharmakon 2018, 6, 379.

6. Majors, R.; LCGC North Am. 2015, 33, 20.

7. Majors, R.; LCGC Eur. 2012, 25, 31.

8. Kirkland, J. J.; J. Chromatogr. Sci. 1996, 34, 309.

9. Espinosa, S.; Bosch, E.; Rosés, M.; Anal. Chem. 2002, 74, 3809.

10. Heinisch, S.; Rocca, J. L.; J. Chromatogr. A 2004, 1048, 183.

11. Agrafiotou, P.; Ràfols, C.; Castells, C.; Bosch, E.; Rosés, M.; J. Chromatogr. A 2011, 1218, 4995.

12. Vanhoenacker, G.; Sandra, P.; Anal. Bioanal. Chem. 2008, 390, 245. 
13. Zarzycki, P. K.; Ohta, H.; Saito, Y.; Jinno, K.; Anal. Bioanal. Chem. 2008, 391, 2793.

14. Zhu, C.; Goodall, D. M.; Wren, S. A. C.; LCGC Eur. 2004, 17, 530.

15. Thompson, J. D.; Carr, P. W.; Anal. Chem. 2002, 74, 1017.

16. Snyder, L. R.; Kirkland, J. J.; Dolan, J. W.; Introduction to Modern Liquid Chromatography, $3^{\text {rd }}$ ed., Wiley: New York, 2010.

17. Claessens, H. A.; van Straten, M. A.; Kirkland, J. J.; J. Chromatogr. A 1996, 728,259

18. Teutenberg, T.; Tuerk, J.; Holzhauser, M.; Giegold, S.; J. Sep. Sci. 2007, 30, 1101.

19. Kirkland, J. J.; van Straten, M. A.; Claessens, H. A.; J. Chromatogr. A 1995, 695, 3 .
20. Fonseca, D. A.; Gutiérrez, H. R.; Collins, K. E.; Collins, C. H.; J. Chromatogr. A 2004, 1030, 149.

21. Faria, A. M.; Jardim, I. C. S. F.; Collins, C. H.; J. Chromatogr. Sci. 2009 , 47, 734.

22. Berthod, A.; J. Chromatogr. 1991, 549, 1.

23. Kirkland, J. J.; J. Chromatogr. A 2004, 1060, 9.

24. Ide, M.; Canck, E. D.; van Driessche, I.; Lynen, F.; van der Voort, P.; RSC Adv. 2015, 5, 5546.

25. Faria, A. M.; Tonhi, E.; Collins, K. E.; Collins, C. H.; J. Sep. Sci. 2007, 30, 1844.

26. Teutenberg, T.; Hollebekkers, K.; Wiese, S.; Boergers, A.; J. Sep. Sci. 2009, 32, 1262 